\title{
A história de pidgins e crioulos contra o excepcionalismo
}

\author{
Rodrigo Lazaresko MADRID (1) \\ Universidade de São Paulo (USP)
}

\section{RESUMO}

A conferência de Salikoko S. Mufwene tem como tema o surgimento de línguas pidgin e a relação destas com línguas crioulas. O conferencista introduz a abordagem tradicional (em especial a que analisa pidgins como formas ancestrais ou iniciais de línguas crioulas) para criticá-las. Por meio de uma argumentação de base historiográfica, Mufwene expõe a abordagem uniformitária, para a qual pidgins e línguas crioulas não têm peculiaridades estruturais que justifiquem sua especificidade em comparação a outras línguas surgidas em contextos de contato. Além disso, a discrepância cronológica e geográfica que existe no uso dos dois termos é colocada como evidência da ausência de relação genética entre essas línguas. Ao re-

○ OPEN ACCESS

EDITADO POR Raquel Freitag

REVISADO POR Ana Livia Agostinho

DATAS

Recebido: 14/05/2020 Aceito: 26/05/2020 Publicado: 30/06/2020

COMO CITAR

Madrid, R. L. (2020). A história de pidginse crioulos contra o excepcionalismo. Revista da Abralin, v. 19, n. 2, p. 1-5, 2020. traçar o surgimento da classificação de pidgins e crioulos, Mufwene associa o exclusivismo atribuído pelos conceitos à ideologia colonialista vigente na Europa durante o século XIX.

\section{ABSTRACT}

Salikoko S. Mufwene's conference presents the emergence of pidgins and their relations with creole languages. The speaker describes the traditional approach (which analyses pidgins as ancestor or initial forms of creole languages) aiming to criticize it. Through a historiography-based argumentation, Mufwene introduces the uniformitarian approach, to which pidgins and creoles have no structural peculiarities that justify a differentiation from other languages that emerged from language contact. Moreover, the chronological and geographical diversion in the usage of those two concepts is argued to be an evidence of the unrelatedness of the language types to which they refer. By tracing back the emergence of the pidgins and creole concepts, Mufwene tributes the exclusivism 


\section{REVISTA DA ABRALIN}

assigned to those languages to the colonialist ideology that prevailed in Europe during the 19th century.

\section{PALAVRAS-CHAVE}

Pidgin. Línguas crioulas. Contato linguístico.

\section{KEYWORDS}

Pidgin. Creole languages. Language contact.

A conferência de Salikoko S. Mufwene, professor do departamento de Linguística da Universidade de Chicago, é de especial interesse aos linguistas que buscam compreender a emergência de novas variedades linguísticas a partir do contato de línguas distintas.

Mufwene inicia a conferência alertando que sua fala pode ser considerada subversiva, devido ao rumo que as evidências históricas o conduziram. Isso se deve ao fato de sua proposta para o estudo de pidgins e de crioulos divergir de parte considerável da literatura sobre o tema, que observa uma excepcionalidade nessas línguas devida ao contexto em que surgiram. O principal argumento da conferência está na consideração do contexto de surgimento não apenas das línguas em questão, mas também da abordagem adotada pelos estudos sobre elas.

Mufwene denomina a abordagem a que se opõe de 'narrativa tradicional'. Esta trata os pidgins como "línguas quebradas" (broken languages), advindas do contato esporádico entre europeus e populações autóctones de diferentes regiões do mundo iniciado com as grandes navegações no século XV. Esses europeus não teriam interesse em aprender as línguas locais, e as populações nativas não conseguiriam aprender as línguas europeias adequadamente em função da baixa disponibilidade de input da língua alvo. Pidgins, então, seriam uma espécie de língua franca menos complexa e desenvolvida, a partir da qual os crioulos teriam evoluído nas colônias de assentamento que adotaram o plantation como forma de organização da economia. Isso ocorria em função da segregação social imposta pelo sistema tanto no trabalho rural como em eventuais quilombos e fortalezas. Neste momento o conferencista apresenta o primeiro dado histórico que contradiz essa visão: os pidgins falados na Nigéria e em Camarões não se enquadram nessa relação entre história e evolução linguística.

Mufwene considera que essa narrativa, apesar de equivocada, tem sido conveniente ao longo dos anos. Essa abordagem, que parte da premissa de que os sistemas evoluem de formas mais simples para mais complexas, permite associar as diferenças linguísticas entre europeus e não europeus a diferentes estágios de evolução humana, em consonância com as teorias sociais vigentes na Europa do século XIX.

Na sequência, apresentam-se outros fatos históricos que foram ignorados e que colocam a 'narrativa tradicional' em disputa. Primeiramente, a história das próprias línguas europeias mostra que sua evolução ocorreu de estruturas morfológicas mais complexas para formas mais simples. O 


\section{REVISTA DA ABRALIN}

argumento seguinte abrange dois aspectos que distanciam os conceitos de 'pidgin' e 'crioulo': um cronológico e outro geográfico. Enquanto o termo 'crioulo' surgiu no século XVI e foi usado para se referir a uma variedade linguística colonial apenas no século XVII, o termo 'pidgin' emergiu somente no final do século seguinte. Além da distância temporal, os termos têm suas origens em locais distintos: 'crioulo' surgiu nas Américas, ao passo que 'pidgin' se originou em Cantão, na China. Esses fatos contrariam a reivindicação de que pidgins seriam estágios ancestrais de crioulos.

Mufwene, então, exibe um mapa-múndi, em que se destacam as áreas onde são falados pidgins e crioulos. O mapa deixa claro que essas regiões se encontram em distribuição complementar: onde se fala pidgin não se fala crioulo e vice-versa. O Havaí apresenta uma possível exceção, mas que é descartada com base nas diferentes origens do pidgin e do crioulo falados nas ilhas: enquanto o pidgin teria emergido nos latifúndios rurais, o crioulo teria surgido nos centros urbanos.

Outro fato histórico que Mufwene apresenta como tendo sido ignorado pela narrativa tradicional é a heterogeneidade e longevidade do empreendimento colonial. Ao retomar o início da expansão marítima europeia, nota-se a ausência de pidgins de base castelhana e portuguesa - línguas faladas pelas potências imperiais europeias do século XV que praticamente dividiam as rotas comerciais mundiais à época. O comércio é um dos argumentos utilizados na narrativa tradicional para o surgimento dos pidgins, uma vez que se realizava em um contexto de interação esporádico e com finalidade específica. Mufwene chama a atenção para o comércio realizado entre os africanos e os árabes antes do processo de expansão comercial europeia e questiona: quantos pidgins terão surgido dessas trocas comerciais? Não há trabalhos que respondam essa pergunta.

A análise histórica do comércio entre europeus e africanos passa a ser o foco da conferência. Os principais produtos oferecidos por africanos e adquiridos por europeus eram commodities de altíssimo valor, com destaque para ouro, marfim e seres humanos. O comércio desses itens não era realizado por comerciantes individuais e pequenos proprietários em mercados temporários: as transações envolviam grandes companhias e altos valores monetários. Assim, havia protocolos a serem seguidos por empresas europeias que comercializavam com governantes de sociedades organizadas na África. Isso evidencia que o período entre os primeiros encontros e a consolidação do comércio era longo e envolvia intérpretes africanos e europeus erradicados na África no contexto da Reconquista e da Inquisição na Península Ibérica. Essa constatação desfavorece a concepção da emergência de línguas como fruto de um aprendizado ineficiente ou de uma comunicação simplificada baseada fortemente na gestualidade.

Na sequência, Mufwene analisa dados linguísticos de pidgins e variedades não padrão do inglês, para defender que tanto pidgins como crioulos emergiram por meio de basiletalização, ou seja, por divergirem do modelo das línguas europeias falado à época. A diferença estaria no grau de divergência: os pidgins divergem mais das línguas europeias que os crioulos.

Mufwene atribui ao racismo ideológico preponderante no século XIX o interesse em distinguir e especificar variedades linguísticas não europeias: até esse século, não há registros de variedades linguísticas atribuídas exclusivamente às populações negras ou africanas, ainda que as colônias tenham se iniciado ao menos dois séculos antes. É também no século XIX que a maioria dos pidgins 


\section{REVISTA DA ABRALIN}

emergem, em grande parte em função da mudança drástica que o comércio globalizado sofreu com o crescimento da participação britânica nas rotas e colônias. Não seria coincidência, portanto, a escassez de pidgins lexificados por outras línguas europeias em vez do inglês.

A conferência se encerra com a apresentação das histórias do Nigerian Pidgin English (NPE) e do Cameroon Pidgin English (CPE) como evidência de que os pidgins são mais recentes que os crioulos e, consequentemente, não podem ser considerados formas anteriores ou ancestrais destes. Para além disso, Mufwene criticou o Excepcionalismo Crioulo - a concepção identificada por DeGraff $(2003 ; 2005)$ de que pidgins e crioulos têm características únicas - pelo fato de não haver um conjunto de traços estruturais que sejam exclusivos à gramática de línguas crioulas.

Após a conferência, Mufwene respondeu algumas perguntas dos participantes e pôde esboçar ideias novas e reforçar alguns argumentos. Mencionou que sua postura uniformitária não permite classificar novas variedades linguísticas emergentes como crioulo ou pidgin, e que a própria utilização desses conceitos já desencadeia um viés metodológico que prejudica a descrição dessas línguas.

How Pidgins Emerged? Not as We Have Been Told é uma excelente introdução à visão de Salikoko Mufwene sobre a emergência de variedades linguísticas em situações de contato. Dada a limitação do tempo de uma conferência, a argumentação se concentra na oposição entre pidgin e crioulo em termos cronológicos e geográficos, com indicações de semelhanças em termos estruturais, inclusive com línguas que não recebem essa classificação. Ele defende que os termos estão ancorados em uma percepção europeia sobre os falantes de variedades não europeias de suas línguas, sem embasamento nas estruturas linguísticas propriamente ditas. Essa argumentação encontra-se mais aprofundada em obras anteriores $(2001,2008)$.

Dessa maneira, trata-se de uma apresentação subversiva que provoca uma reflexão não apenas sobre os estudos sobre línguas em contato, mas também da própria descrição linguística. Ao retraçar a história dos processos de colonização, Mufwene escancara como as descrições linguísticas estão imbuídas do colonialismo e do racismo que predominava o pensamento europeu do século XIX. O trabalho de Mufwene - assim como o de DeGraff $(2003,2005)$ já mencionado, de Aboh (2015) entre outros - é fundamental para que, no século XXI, a Linguística supere as tradições colonialistas.

\section{REFERÊNCIAS}

$\mathrm{ABOH}, \mathrm{E}$. O. The emergence of hybrid grammars: language contact and change. Cambridge: Cambridge University Press, 2015.

DEGRAFF, M. Against Creole exceptionalism. Language, Cambridge, vol.79, n. 2, p. 391-410, 2003. DOI: 10.1353/lan.2003.0114

DEGRAFF, M. Linguists' most dangerous myth: The fallacy of Creole Exceptionalism. Language in society 34, p. 533-591, 2005. DOI: 10.10170S0047404505050207 


\section{REVISTA DA ABRALIN}

HOW pidgins emerged? Not as we have been told. Conferência apresentada por Salikoko S. Mufwene [s.l., s.n.], 2020.1 vídeo (1h 19min 11s). Publicado pelo canal da Associação Brasileira de Linguística. Disponível em: https://www.youtube.com/watch?v=9nsTHFxq-9w. Acesso em: 07 mai 2020.

MUFWENE, S. S. The ecology of language evolution. New York: Cambridge University Press, 2001. 